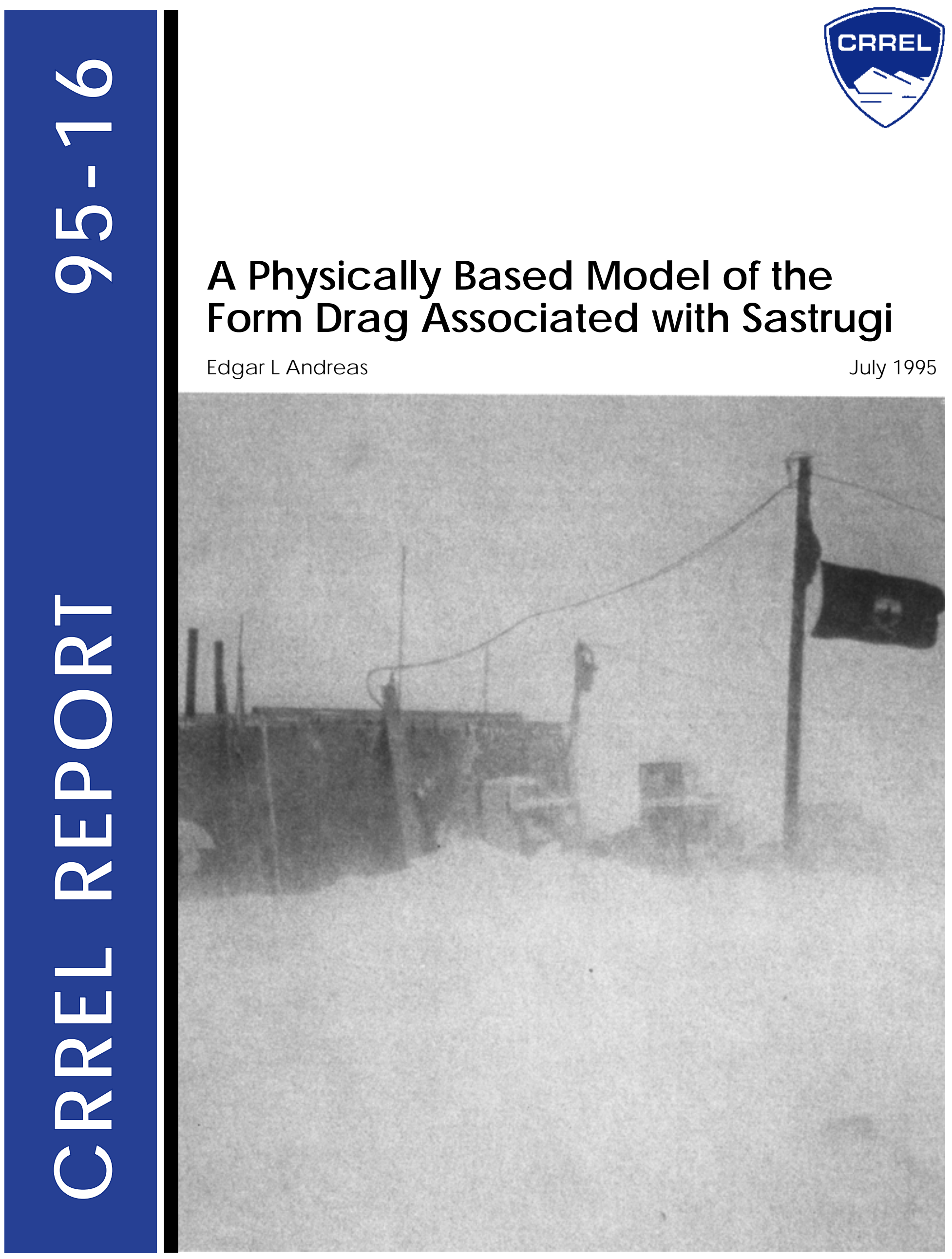




\begin{abstract}
On Ice Station Weddell, some characteristics of the neutral-stability air-ice drag coefficient at a reference height of $10 \mathrm{~m}\left(C_{\mathrm{DN} 10}\right)$ were observed that had not been documented before. The main finding was that wind-driven snow continually alters the sea ice surface; the resulting snowdrifts determine how large $C_{\mathrm{DN} 10}$ is. In particular, this report describes three observations and attempts to explain them: 1) $C_{\mathrm{DN} 10}$ is near $1.5 \times 10^{-3}$ when the wind is well aligned with the drifted snow; 2) $C_{\mathrm{DN} 10}$ is near $2.5 \times 10^{-3}$ when the wind makes a large angle with the dominant orientation of the snowdrifts; 3 ) $C_{\mathrm{DN} 10}$ can increase by $20 \%$ if, after being well aligned with the drift patterns, the mean wind direction shifts by as litte as $20^{\circ}$. To investigate this behavior of $C_{\mathrm{DN} 10}$, this report adapts a model developed by Raupach that partitions the total surface stress into contributions from form drag and skin friction. With reasonable choices for free model parameters and with little fine-tuning, this physically based model can reproduce the three main observations. In other words, the model seems to include the basic physics of air-ice momentum exchange. This modeling implies that $10-\mathrm{cm}$-high sastrugi-like roughness elements, rather than pressure ridges, sustain most of the form drag over compact sea ice in the western Weddell Sea. Lastly, the report speculates on what the observations and this model say about how to parameterize $C_{D N 10}$ over snow-covered sea ice.
\end{abstract}

Cover: Drifting snow on Ice Station Weddell. Photograph by Keran Claffey.

For conversion of SI units to non-SI units of measurement consult Standard Practice for Use of the Intemational System of Units (SI), ASTM Standard E38093, published by the American Society for Testing and Materials, 1916 Race St., Philadelphia, Pa. 19103. 


\section{CRREL Report 95-16}

US Army Corps

of Engineers

Cold Regions Research \&

Engineering Laboratory

\section{A Physically Based Model of the Form Drag Assoc iated with Sastrugi}

Edgar LAndreas

J uly 1995 


\section{PREFACE}

Dr. Edgar L Andreas, Physicist, Snow and Ice Division, Research and Engineering Directorate, U.S. Army Cold Regions Research and Engineering Laboratory, prepared this report. He thanks Keran J. Claffey, who played a large role in collecting the data on Ice Station Weddell, and R.B. Haehnel and Dr. S.C. Colbeck, who reviewed the manuscript.

The Office of Polar Programs at the National Science Foundation supported this work through grants OPP-90-24544 and OPP-93-12642, and the Department of the Army supported it through Project 4A161102AT24.

The contents of this report are not to be used for advertising or promotional purposes. Citation of brand names does not constitute an official endorsement or approval of the use of such commercial products. 


\section{CONTENTS}

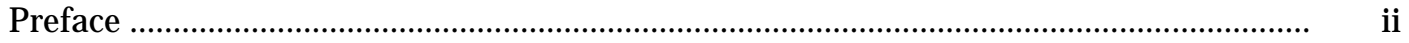

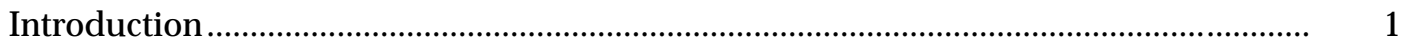

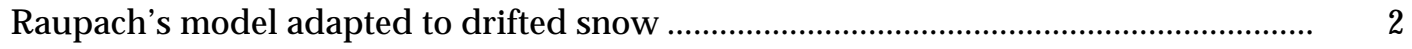

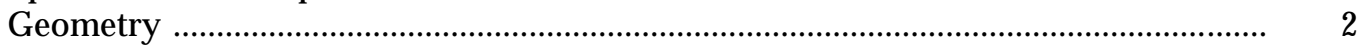

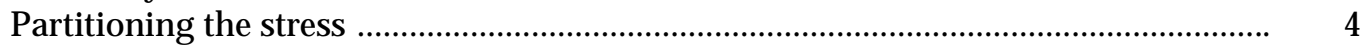

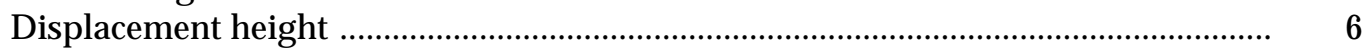

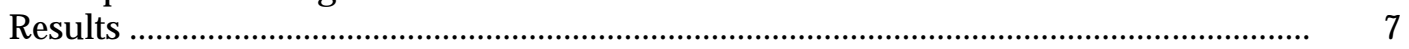

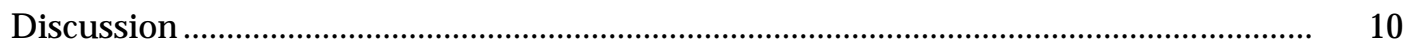

Primary roughness elements ................................................................................ 10

Parameterizing the drag coefficient ................................................................... 10

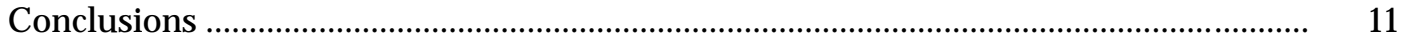

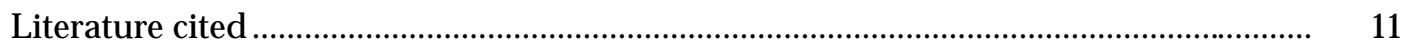

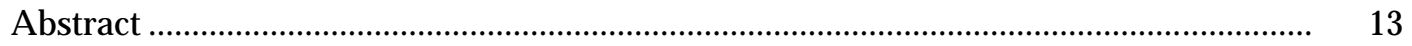

\section{ILLUSTRATIONS}

Figure

1. Time series of the Ice Station Weddell $C_{\mathrm{DN} 10}$ values and hourly averages of the wind speed and direction .............................................................................. 1

2. Snow and ice surface elevations near ISW profile tower on Julian Day 78 ............ 3

3. Geometry of the sastrugi-like snowdrifts being modeled ........................................ 3

4. Model calculation of $C_{\mathrm{DN} 10}$ as a function of the wind orientation with respect to the dominant axis of the sastrugi ........................................................... 8

5. Stress partitioning versus the mean wind direction with respect to the dominant axis of the sastrugi

6. Computed displacement height scaled by sastrugi height versus the direction of the mean wind with respect to the sastrugi 


\title{
A Physically Based Model of the Form Drag Associated with Sastrugi
}

\author{
EDGAR L ANDREAS
}

\section{INTRODUCTION}

The neutral-stability, 10-m air-ice drag coefficients $\left(C_{\mathrm{DN} 10}\right)$ reported by Andreas and Claffey (1995; henceforth, AC95) clearly depend on how wind-driven snow alters the sea ice surface. Figure 1 shows the time series of Ice Station Weddell (ISW) $C_{\mathrm{DN} 10}$ values and hourly averages of the wind speed and direction measured at $5 \mathrm{~m}$. These $C_{\mathrm{DN} 10}$ values range between $1.27 \times 10^{-3}$ and $2.54 \times 10^{-3}$ but are not randomly scattered between these limits. Rather, they generally cluster or depend coherently on time. For example, in AC 95 we focused on the events on Julian days 64 and 65 and 79 and 80. In Figure 1, we see that, on these days, the 5-m wind speed was typically $8 \mathrm{~m} / \mathrm{s}$ or higher, the wind direction was fairly constant, and $C_{\mathrm{DN} 10}$ decreased consistently with time.

Our explanation for this sequence was that winds of $6-8 \mathrm{~m} / \mathrm{s}$, and higher, redistribute the mobile snow: snowdrifts perpendicular to the wind erode; and the new drifts, built parallel with the mean wind, streamline the surface. Consequently, if these eroding winds persist and their direction remains relatively constant for just 12 hours, $C_{\mathrm{DN} 10}$ will decrease by as much as $30 \%$. If, after establishing a drift pattern, however, the wind shifts by as little as $20^{\circ}$, it will face a rougher surface, and measured $C_{\mathrm{DN} 10}$ values will increase.

There are several other events in Figure 1 that demonstrate this same smoothing in the presence of a moderate, directionally constant wind (for example, see days 86 and 87). Thus, the sequence is repeatable and, in fact, seems to be the key to understanding air-ice momentum exchange in the western Weddell Sea-and probably over most other sea ice regions as well.

Form drag sustained by the snowdrifts must explain the behavior of the $C_{\mathrm{DN} 10}$ values that we observed. Others have also recognized that form
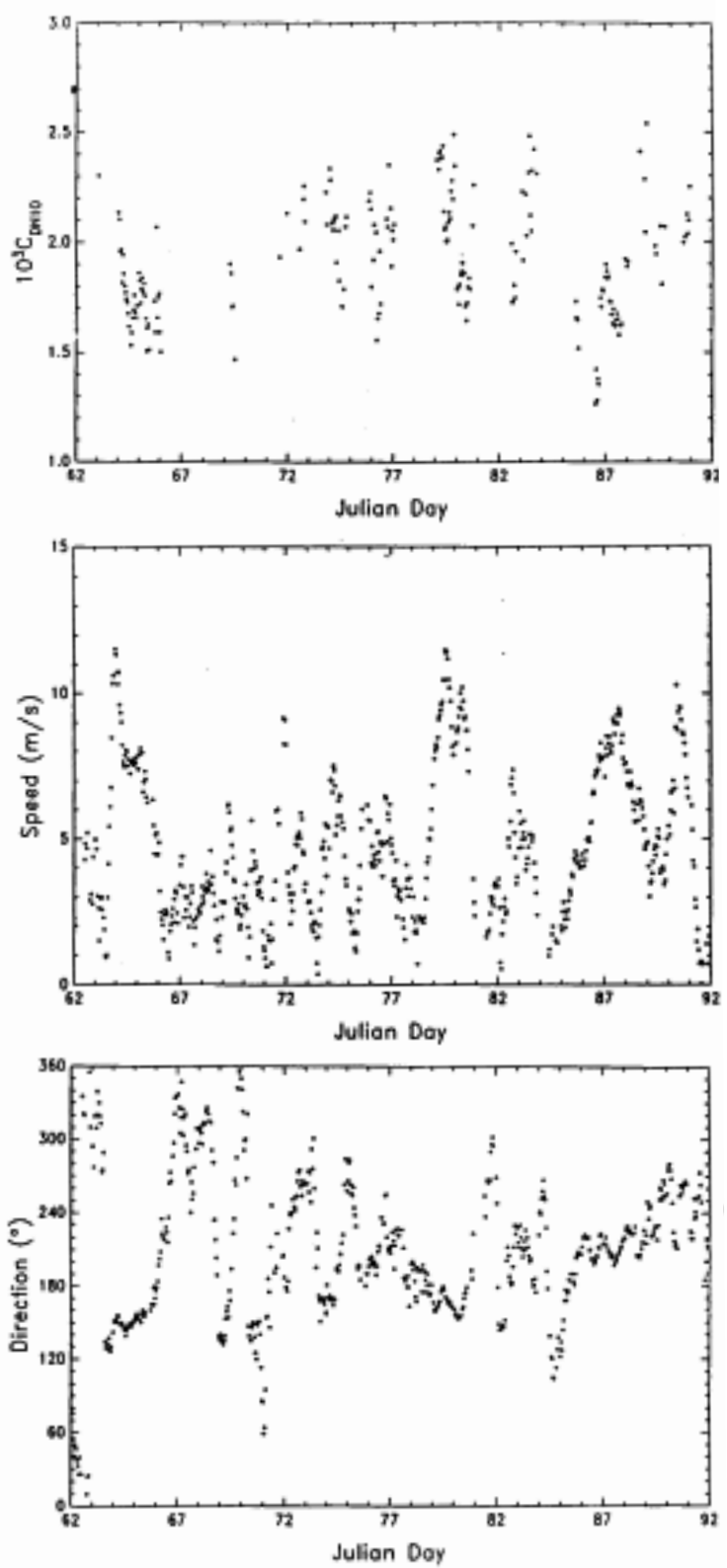

Figure 1. Time series of the Ice Station Weddell (ISW) $C_{D N 10}$ values reported in Andreas and Claffey (1995) and hourly averages of the wind speed and direction at $5 \mathrm{~m}$. 
drag can, at times, be an important means for transferring momentum to a surface. For example, Lettau (1969) offered a heuristic formula involving obstacle geometry and silhouette area to parameterize the roughness lengths that Kutzbach (1961) measured during his famous bushel basket experiment on Lake Mendota. Arya (1973, 1975) assumed that pressure ridges were the roughness elements responsible for most of the form drag over Arctic sea ice and developed a model to partition the total stress into skin friction and form drag on the basis of ridging intensity. Banke et al. $(1976,1980)$ investigated the pressure distribution around Arctic pressure ridges 1-3 $\mathrm{m}$ high in an attempt to determine the form drag coefficient for these. But their ultimate parameterization for $C_{\mathrm{DN} 10}$ (also Banke and Smith 1973) is more in line with our findings; they showed that

$$
10^{3} C_{\mathrm{DN} 10}=1.10+0.072 \xi
$$

where $\xi$ (in centimeters) is the root-mean-square surface roughness for roughness elements with wavelengths shorter than $13 \mathrm{~m}$. That is, the smaller scale roughness dominates the momentum exchange. Jackson and Carroll (1978) reached the same conclusion. They showed that the angle between the mean wind and the dominant axis of the sastrugi at the South Pole determined the roughness length; they then developed a model based on Lettau's to explain this effect.

More recently, Raupach (1992; henceforth, R92; also Raupach et al. 1993) developed a more sophisticated model, based on dimensional analysis and two physically reasonable hypotheses, to partition the total surface stress into contributions from form drag and from the stress on the underlying surface. That model is the basis of the analysis here. I adapt Raupach's model to evaluate the stress partitioning for a field of sastrugilike snowdrifts. That model predicts the drag coefficient evaluated at the top of the roughness elements; I show how this quantity is related to $C_{\mathrm{DN} 10}$, which, in turn, is monotonically related to the roughness length $z_{0}$ through

$$
C_{\mathrm{DN} 10}=k^{2}\left\{\ln \left[(10-d) / z_{0}\right]\right\}^{-2} .
$$

Here, $k(=0.4)$ is the von Kármán constant, and $z_{0}$ and the displacement height $d$ must be in meters.

My objective is to see whether, with reasonable choices for snowdrift geometry and other free model parameters, R92's model can account for the behavior of $C_{\mathrm{DN} 10}$ at ISW that we documented in AC95. In particular, the three main observations that I hope to explain are as follows:

1. $C_{\mathrm{DN} 10}$ is near $1.5 \times 10^{-3}$ when the wind is aligned with a well-developed field of drifted snow.

2. $C_{\mathrm{DN} 10}$ is near $2.5 \times 10^{-3}$ when the mean wind direction makes a large angle (say 50-140 ${ }^{\circ}$ ) with the dominant axis of the drifts.

3. $C_{\mathrm{DN} 10}$ can increase by roughly $20 \%$ if, after being aligned with a developed (or developing) field of drifted snow, the wind turns by as little as $20^{\circ}$.

\section{RAUPACH'S MODEL ADAPTED TO DRIFTED SNOW}

\section{Geometry}

Because during our deployment on ISW the wind was directionally quite variable, the surface never developed the deep, elaborate fields of sastrugi that Mellor (1965) and Jackson and Carroll (1978) observed on the Antarctic continent. Rather, on ISW, the drifts were sparsely distributed and rudimentary. When the wind reached $6-8 \mathrm{~m} / \mathrm{s}$, linear sastrugi-like drifts would begin forming behind any protruding obstacles. The drifts would grow as the wind persisted; but when the wind direction changed, these drifts would erode in winds above the 6- to $8-\mathrm{m} / \mathrm{s}$ threshold. Thus, the drifts that determined the surface roughness on ISW were generally small. The scour marks that Allen (1965) described and named scour-remnant ridges may well be precursors to these rudimentary sastrugi.

Figure 2 shows a typical leveling profile of the snow and sea ice surfaces in the vicinity of the profiling mast described in AC95. We made seven such leveling surveys during our deployment on ISW. The profiles show that snow tends to collect around obstacles in the underlying ice. The root-mean-square (rms) roughness of the snow surface in this particular profile is $11 \mathrm{~cm}$; its icesurface roughness is $9 \mathrm{~cm}$. In the seven surface profiles that we collected, the rms snow-surface roughness ranged from 9 to $26 \mathrm{~cm}$; the ice-surface roughness ranged from 9 to $28 \mathrm{~cm}$. A value in this range is a reasonable choice for the nominal height of the snow-surface roughness elements.

Figure 3 shows the idealized geometry of the roughness elements that I will treat with R92's model. These are rudimentary sastrugi with 


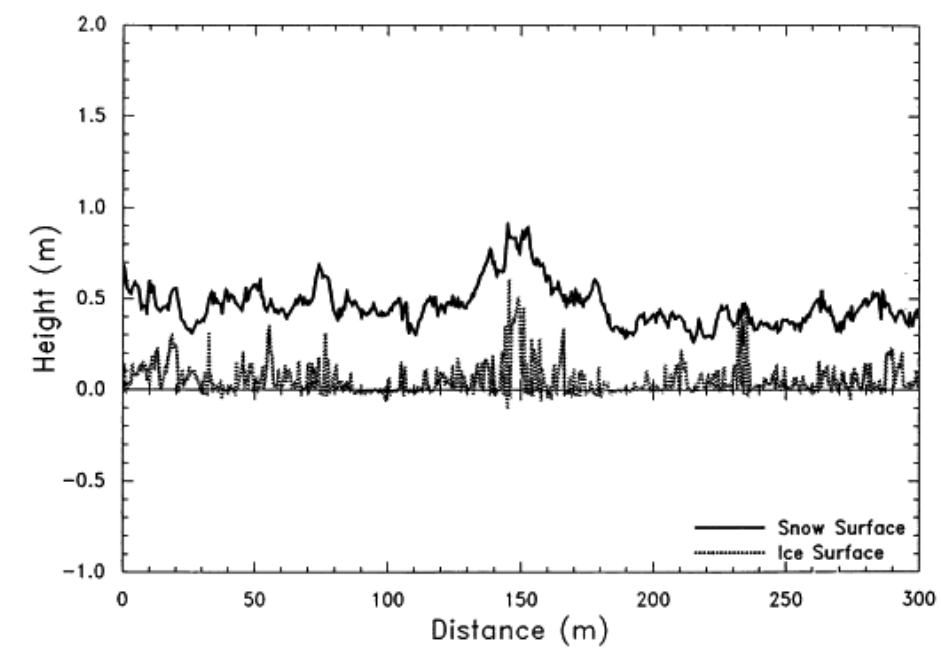

Figure 2. Snow and ice surface elevations near our ISW profile tower on Julian day 78 (in 1992). The sampling interval was $0.5 \mathrm{~m}$.

The profiling line is not necessarily aligned with the mean wind.
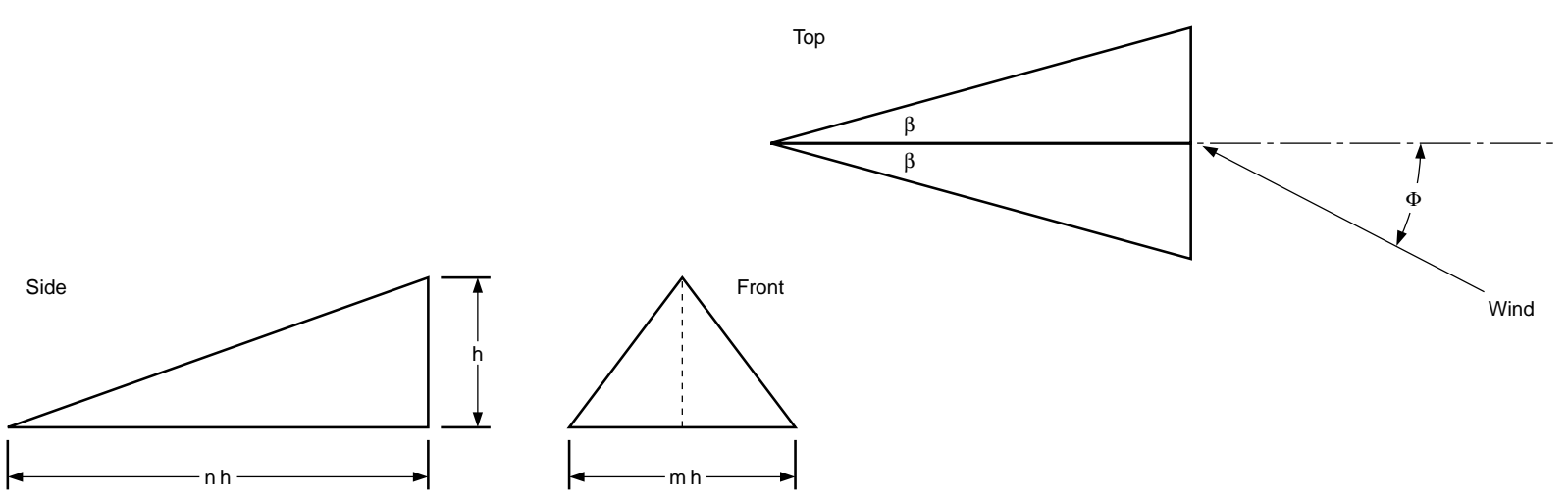

Figure 3. Geometry of the sastrugi-like snowdrifts being modeled here.

height $h$, width $m h$, and length $n h$. The angle $\Phi$ describes how the mean wind is oriented with respect to the sastrugi. When the wind has been blowing with constant direction at speeds of $6-8 \mathrm{~m} / \mathrm{s}$, or higher, for several hours, $\Phi$ will be zero.

From the discussion in the penultimate paragraph, we see that $h$ is $5-20 \mathrm{~cm}$. Descriptions of drifted snow in the literature (Finney 1939, Mellor 1965, Jackson and Carroll 1978) and Plate's (1971, Figure 4.17) pressure distribution around roughness elements similar to that in Figure 3 suggest that $n$ is about 10. From Mellor's (1965) description of sastrugi, I assume that $m$ is about 4. Notice, these parameters imply that, in Figure 3

$$
\beta=\arctan (m / 2 n)=11.3^{\circ} .
$$

One of the key parameters in R92's model is $\lambda$, the frontal area of a typical roughness element per unit ground area. Suppose the fraction of the area covered by the sastrugi-like roughness elements is $\gamma$. Thus, from Figure 3 , the unit area represented by each roughness element is $m n h^{2} / 2 \gamma$. The base length of the triangular frontal area that each roughness element presents to the wind, $L(\Phi)$, is a function of $\Phi$. Likewise, the silhouette area presented, $A(\Phi)$, is simply

$$
A(\Phi)=\frac{1}{2} h L(\Phi) .
$$

Consequently, $\lambda$ is also a function of $\Phi$

$$
\lambda(\Phi)=\frac{2 \gamma A(\Phi)}{m n h^{2}}=\frac{\gamma L(\Phi)}{m n h} .
$$

In Figure 3, we see that there are four $\Phi$ regions for which a roughness element presents different faces to the wind for $0 \leq \Phi \leq 180^{\circ}$ (symmetric for $\left.0 \geq \Phi \geq-180^{\circ}\right)$. These and the associated values of $L, A$ and $\lambda$ follow. 
Region I: $0^{\circ} \leq \Phi \leq \beta$

Here the wind sees only the front triangular face. Thus

$$
\begin{aligned}
& L(\Phi)=m h \cos \Phi \\
& A(\Phi)=\left(m h^{2} / 2\right) \cos \Phi \\
& \lambda(\Phi)=(\gamma / n) \cos \Phi .
\end{aligned}
$$

Region II: $\beta \leq \Phi \leq 90^{\circ}$

Here the wind sees both the front triangular face and the side ridge. Thus

$$
\begin{aligned}
& L(\Phi)=n h \sin \Phi+(m h / 2) \cos \Phi \\
& A(\Phi)=\left(h^{2} / 2\right)[n \sin \Phi+(m / 2) \cos \Phi] \\
& \lambda(\Phi)=\gamma\left[m^{-1} \sin \Phi+(2 n)^{-1} \cos \Phi\right] .
\end{aligned}
$$

Region III: $90^{\circ} \leq \Phi \leq 180^{\circ}-\beta$

Here the wind sees only the side ridge. Thus

$$
\begin{aligned}
& L(\Phi)=n h \sin \Phi-(m h / 2) \cos \Phi \\
& A(\Phi)=\left(h^{2} / 2\right)[n \sin \Phi-(m / 2) \cos \Phi] \\
& \lambda(\Phi)=\gamma\left[m^{-1} \sin \Phi-(2 n)^{-1} \cos \Phi\right] .
\end{aligned}
$$

Region IV: $180^{\circ}-\beta \leq \Phi \leq 180^{\circ}$

Here the flow sees both side ridges as it approaches from the rear of the drift. Thus

$$
\begin{aligned}
& L(\Phi)=-m h \cos \Phi \\
& A(\Phi)=-\left(m h^{2} / 2\right) \cos \Phi \\
& \lambda(\Phi)=-(\gamma / n) \cos \Phi .
\end{aligned}
$$

\section{Partitioning the stress}

R92's intent was to partition the total surface stress $(\tau)$ into contributions from form drag $\left(\tau_{R}\right)$ and from stress on the underlying surface (the skin friction, $\tau_{\mathrm{S}}$ ). In general

$$
\tau=\tau_{\mathrm{R}}+\tau_{\mathrm{S}}
$$

There is another potential sink for the momentum in eq 10 that R92 did not treat. Over erodible surfaces, saltating particles may extract momentum from the air because of their inertia. Neither $\tau_{\mathrm{R}}$ nor $\tau_{\mathrm{S}}$ reflects this momentum exchange. That saltation layer, however, is quite thin-on the order of a centimeter (Owen 1964, Radok 1968,
AC95). Thus, since R92 models eq 10 for heights of order $h$ and higher-well above the saltation layer-eq 10 need not include a term to account for particle inertia. Above the saltation layer, the concentration of blowing and drifting snow is too low to affect the dynamics of the flow.

R92 modeled the stress on the underlying surface as

$$
\tau_{\mathrm{S}}(\lambda)=\rho C_{\mathrm{Sh}} U_{\mathrm{h}}^{2} \exp \left[-c_{1} \lambda(\Phi) \frac{U_{\mathrm{h}}}{u_{*}}\right] .
$$

Here, $C_{S h}$ is the drag coefficient of the underlying surface referenced to a height $h$, which is where the wind speed $U_{\mathrm{h}}$ is evaluated. Also in eq 11, $\rho$ is the air density; $u_{*}$, the friction velocity, $u_{*}=(\tau / \rho)^{1 / 2}$; and $c_{1}$, an empirical constant. The exponential term in eq 11 accounts for the sheltering of the underlying surface by the roughness elements. That is, when the roughness elements are small or sparse and $\lambda(\Phi)$, thus, is small, eq 11 reduces to $\tau_{\mathrm{S}}=\rho C_{\mathrm{Sh}} U_{\mathrm{h}}^{2}$, the usual expression for the skin friction over a smooth surface. On the other hand, when the roughness elements have a large frontal area or are densely packed, $\lambda(\Phi)$ is large, and $\tau_{S}$ approaches zero. In this case, the roughness elements completely shelter the surface; thus, skin friction can provide none of the stress.

We can infer the value of $C_{S h}$ appropriate for smooth, snow-covered surfaces from Overland's (1985) review and from the measurements reported by Banke et al. (1980) and Kondo and Yamazawa (1986). The lowest value for $C_{\mathrm{DN} 10}$ reported by Overland and Kondo and Yamazawa is roughly $1.1 \times 10^{-3}$. Coincidentally, Figure 4 in Banke et al. implies that the value of $C_{\mathrm{DN} 10}$ for completely smooth sea ice is $1.10 \times 10^{-3}$. Call this minimum skin friction coefficient $C_{\mathrm{S} 10}$.

Converting $C_{\mathrm{S} 10}$ to $C_{\mathrm{Sh}}$, however, is not straightforward: We do not know the displacement height $d$ a priori; and near the tops of the roughness elements, the semi-logarithmic profile law (see eq 2) is not accurate. I will explain how I deal with these complications later; here, suffice it to say, I obtain $C_{\mathrm{Sh}}$ from $\mathrm{C}_{\mathrm{S} 10}$.

R92 wrote a general expression for the force caused by form drag on an isolated roughness element as

$$
F_{\mathrm{D}}=\rho C_{\mathrm{R}} A U_{\mathrm{h}}^{2}
$$

where $C_{\mathrm{R}}$ is the drag coefficient of the obstacle, and $A$ is its silhouette area. Here, I must modify 
Raupach's model, however. In my model, the obstacle's aerodynamic properties likely change as its orientation with the wind changes. Otherwise, the concept of streamlining would be meaningless. Thus, $C_{\mathrm{R}}$ and $A$ must depend on $\Phi$. But because I could find no study in the literature that reported the aerodynamic properties of an obstacle like that depicted in Figure 3, I assume that the drag contributions from the various faces are additive. Mathematically, my hypothesis is

$$
F_{\mathrm{D}}(\Phi)=\rho U_{\mathrm{h}}^{2} \sum_{i} C_{\mathrm{Ri}}(\Phi) A_{\mathrm{i}}(\Phi)
$$

where $C_{\mathrm{Ri}}$ is the drag coefficient for a particular face of the sastrugi-like obstacle, and $A_{\mathrm{i}}$ is the silhouette area of that face. The sum is over all faces presented to the wind at angle $\Phi$.

The obstacle in Figure 3 presents only three faces. When $0^{\circ} \leq \Phi \leq 90^{\circ}$, the wind can see the front triangular face; this has form drag coefficient $C_{R 1}$. When $\beta \leq \Phi \leq 180^{\circ}-\beta$, the wind can see the side ridge; this has drag coefficient $C_{R 2}$. When $180^{\circ}-\beta \leq \Phi \leq 180^{\circ}$, the wind can see only the rear silhouette; this has drag coefficient $C_{R 3}$.

As I mentioned, I found no study that evaluated $C_{R}$ for the obstacle geometry I use here. But on reviewing several studies that treated somewhat similar geometries (i.e., Arie and Rouse 1956; Arya 1973, 1975; Banke et al. 1976, 1980; Taylor 1988), I estimated what I feel are representative values for the three faces. Here, I use $C_{R 1}=0.10$, $C_{\mathrm{R} 2}=0.30$, and $C_{\mathrm{R} 3}=0.30$.

Continuing now with R92's model, if $p$ roughness elements cover a ground area $S$, the stress they produce through form drag is

$$
\tau_{\mathrm{R}}(\Phi, p)=\frac{p}{S}\left[\rho U_{\mathrm{h}}^{2} \sum_{i} C_{\mathrm{Ri}}(\Phi) A_{\mathrm{i}}(\Phi)\right]\left(1-\frac{V}{S h}\right)^{p} .
$$

Here, $V$ is the volume sheltered by an individual roughness element; the term raised to power $p$, thus, represents a mutual sheltering effect.

In my model, from eq 5

$$
\frac{p}{S}=\frac{2 \gamma}{m n h^{2}}=\frac{\lambda(\Phi)}{A(\Phi)}
$$

Using this in eq 14 gives

$$
\begin{aligned}
\tau_{\mathrm{R}}(\Phi, p)= & \frac{\lambda(\Phi)}{A(\Phi)}\left[\rho U_{\mathrm{h}}^{2} \sum_{i} C_{\mathrm{Ri}}(\Phi) A_{\mathrm{i}}(\Phi)\right] \\
& \cdot\left(1-\frac{\lambda(\Phi) V}{p h A(\Phi)}\right)^{p} .
\end{aligned}
$$

In the limit of large $p$

$$
\left(1-\frac{\lambda(\Phi) V}{p h A(\Phi)}\right)^{p} \approx \exp \left[\frac{-\lambda(\Phi) V}{h A(\Phi)}\right] .
$$

Finally, following R92, for $m$ and $n$ greater than 1 , I estimate the sheltered volume to be

$$
V=\frac{1}{2} c_{2} L(\Phi) h^{2} \frac{U_{\mathrm{h}}}{u_{*}}
$$

where $c_{2}$ is another empirical constant. Hence, using eq 5, 17 and 18 in eq 16, we get

$$
\begin{gathered}
\tau_{\mathrm{R}}(\Phi)=\lambda(\Phi)\left[\rho U_{\mathrm{h}}^{2} \sum_{i} C_{\mathrm{Ri}}(\Phi) \frac{A_{\mathrm{i}}(\Phi)}{A(\Phi)}\right] \\
\cdot \exp \left[-\mathcal{C}_{2} \lambda(\Phi) \frac{U_{\mathrm{h}}}{u_{*}}\right]
\end{gathered}
$$

In eq 19, define

$$
\hat{C}_{\mathrm{R}}(\Phi) \equiv \sum_{i} C_{\mathrm{Ri}}(\Phi) \frac{A_{\mathrm{i}}(\Phi)}{A(\Phi)} .
$$

For the four $\Phi$ regions identified earlier, $\hat{C}_{R}$ follows.

Region $\mathrm{I}: 0^{\circ} \leq \Phi \leq \beta$

$$
\hat{C}_{\mathrm{RI}}=C_{\mathrm{R} 1} \text {. }
$$

Region II: $\beta \leq \Phi \leq 90^{\circ}$

$$
\hat{C}_{\mathrm{RII}}=\frac{C_{\mathrm{R} 1} m \cos \Phi+C_{\mathrm{R} 2}[n \sin \Phi-(m / 2) \cos \Phi]}{n \sin \Phi+(m / 2) \cos \Phi} .
$$

Region III: $90^{\circ} \leq \Phi \leq 180^{\circ}-\beta$

$$
\hat{C}_{\text {RIII }}=C_{R 2} \text {. }
$$

Region IV: $180^{\circ}-\beta \leq \Phi \leq 180^{\circ}$

$$
\hat{C}_{\mathrm{RIV}}=C_{\mathrm{R} 3} \text {. }
$$

Combining eq 11, 19 and 20 in eq 10, we get

$$
\begin{aligned}
\tau(\Phi) & =\rho U_{\mathrm{h}}^{2}\left\{C_{\mathrm{Sh}} \exp \left[-c_{1} \lambda(\Phi) \frac{U_{\mathrm{h}}}{u_{*}}\right]\right. \\
& \left.+\lambda(\Phi) \hat{C}_{\mathrm{R}}(\Phi) \exp \left[-c_{2} \lambda(\Phi) \frac{U_{\mathrm{h}}}{u_{*}}\right]\right\} .
\end{aligned}
$$


To make solving eq 22 easier, R92 assumed that $c_{1}=c_{2}=c$; for $c$ he used 0.25 , which provided the best fit to the data that he tested his model against. With this assumption, eq 22 reduces to

$$
\tau(\Phi)=\rho U_{\mathrm{h}}^{2}\left[C_{\mathrm{Sh}}+\lambda(\Phi) \hat{C}_{\mathrm{R}}(\Phi)\right] \exp \left[-c \lambda(\Phi) \frac{U_{\mathrm{h}}}{u_{*}}\right] \text {. }
$$

Notice

$$
\frac{\tau(\Phi)}{\rho U_{\mathrm{h}}^{2}}=\frac{u_{*}^{2}}{U_{\mathrm{h}}^{2}} \equiv C_{\mathrm{Dh}} \equiv \frac{1}{r^{2}}
$$

is the drag coefficient for the total surface stress referenced to height $h$. On inserting this definition and rearranging terms in eq 23 , we get

$$
\begin{aligned}
& \frac{c \lambda(\Phi) r}{2} \exp \left[\frac{-c \lambda(\Phi) r}{2}\right] \\
& =\frac{c \lambda(\Phi)}{2}\left[C_{S h}+\lambda(\Phi) \hat{C}_{R}(\Phi)\right]^{-1 / 2} .
\end{aligned}
$$

This has the form

$$
X \mathrm{e}^{-X}=a
$$

where $a$ is a constant for a given value of $\Phi$.

I solved eq 26 for $X$ using Newton's method; the solution required only two to three iterations. There are multiple solutions to eq 26, however; we must select the right one. As R92 explained, eq 26 has the following properties:

For $0<a<\mathrm{e}^{-1}$, eq 26 has two solutions, $X_{1}$ and $X_{2}$, where $X_{1}<1$ and $X_{2}>1$.

For $a=\mathrm{e}^{-1}, \mathrm{X}=1$.

For $a>\mathrm{e}^{-1}$, there is no solution to eq 26 .

The only nontrivial case is the first of these; and $X_{1}$ is the only physical solution, since $X$ must approach zero as either $\lambda(\Phi)$ or $a$ approaches zero. Thus, to start Newton's method, my first guess was $X=a$.

Solving eq 26 yields $X$, which, in turn, is related to the total drag coefficient we seek

$$
C_{\mathrm{Dh}}^{-1 / 2}=\frac{2 X}{c \lambda(\Phi)}
$$

Notice, to check this solution, we can make an asymptotic approximation in eq 23 . When $\lambda(\Phi)$ is near zero

$$
C_{\mathrm{Dh}}=C_{\mathrm{Sh}}+\lambda(\Phi) \hat{C}_{\mathrm{R}}(\Phi) .
$$

\section{Displacement height}

To convert the total drag coefficient $C_{\mathrm{Dh}}$ to its 10-m value, we need to know the wind speed profile law. When a surface is covered with roughness elements that are much larger than $z_{0}$, it is often necessary to include a displacement height $d$ (Thom 1971) in the semi-logarithmic wind profile. That is

$$
\frac{U(z)}{u_{*}}=\frac{1}{k} \ln \left(\frac{z-d}{z_{0}}\right)
$$

where $U(z)$ is the average wind speed at height $z$.

But near the tops of the roughness elements, eq 29 cannot be accurate because of the enhanced turbulence there created by flow around these obstacles. R92 therefore hypothesized that, for $h \leq z \leq z_{\mathrm{w}}$

$$
\frac{U(z)}{u_{*}}=\frac{1}{k}\left[\ln \left(\frac{z-d}{z_{0}}\right)+\psi\left(\frac{z-d}{z_{\mathrm{w}}-d}\right)\right]
$$

where $\psi$ is a profile influence function similar to the stability corrections required by MoninObukhov similarity. At $z_{\mathrm{w}}$ and above, $\psi$ is zero.

R92 went on to show that

$$
\psi\left(\frac{z-d}{z_{\mathrm{w}}-d}\right)=\frac{z-z_{\mathrm{w}}}{z_{\mathrm{w}}-d}+\ln \left(\frac{z_{\mathrm{w}}-d}{z-d}\right)
$$

and that

$$
z_{\mathrm{w}}-d=c_{\mathrm{w}}(h-d)
$$

where $c_{\mathrm{W}}$ is a constant. He also defined

$$
\psi_{\mathrm{h}} \equiv \psi\left(\frac{h-d}{z_{\mathrm{w}}-d}\right)=\ln \left(c_{\mathrm{w}}\right)+c_{\mathrm{w}}^{-1}-1
$$

which will be useful shortly. Notice, there are errors in two of R92's equations (eq 29 and 31). In an unpublished correction to his paper dated 23 October 1992, Raupach explained that, in light of these errors, $c_{\mathrm{w}}$ is approximately 4 rather than 1.5 , the value he originally gave. Hence, $\psi_{\mathrm{h}}=0.64$, a value independent of surface properties.

Equation 32 implies that

$$
z_{\mathrm{w}}=c_{\mathrm{w}} h+\left(1-c_{\mathrm{w}}\right) d .
$$

With $c_{\mathrm{w}}=4$ and the assumption that $z_{\mathrm{w}}>h$, eq 34 implies that $d<h$ : The displacement height is always less than the height of the roughness elements. 
To obtain $C_{\mathrm{DN} 10}$ from $C_{\mathrm{Dh}}$, we must match the profile laws, eq 29 and 30, at $z_{\mathrm{w}}$. From eq 29 and 32 , we have the following results for $z \geq z_{\mathrm{W}}$

$$
C_{\mathrm{DN} 10}^{-1 / 2} \equiv \frac{U(10)}{u_{*}}=\frac{1}{k} \ln \left(\frac{10-d}{z_{0}}\right)
$$

and

$$
C_{\mathrm{Dz}_{\mathrm{w}}}^{-1 / 2} \equiv \frac{U\left(z_{\mathrm{w}}\right)}{u_{*}}=\frac{1}{k}\left[\ln \left(\frac{h-d}{z_{0}}\right)+\ln \left(c_{\mathrm{w}}\right)\right]
$$

where $h, d, z_{0}$ and $z_{\mathrm{w}}$ must be in meters. Subtracting eq 35 from 36 , we get

$$
C_{\mathrm{Dz}_{\mathrm{w}}}^{-1 / 2}=C_{\mathrm{DN} 10}^{-1 / 2}+\frac{1}{k}\left[\ln \left(\frac{h-d}{10-d}\right)+\ln \left(c_{\mathrm{w}}\right)\right] .
$$

From eq 30-33, for $h \leq z \leq z_{\mathrm{w}}$

$$
C_{\mathrm{Dh}}^{-1 / 2} \equiv \frac{U_{\mathrm{h}}}{u_{*}}=\frac{1}{k}\left[\ln \left(\frac{h-d}{z_{0}}\right)+\psi_{\mathrm{h}}\right]
$$

and

$$
C_{\mathrm{Dz}_{\mathrm{w}}}^{-1 / 2}=\frac{U\left(z_{\mathrm{w}}\right)}{u_{*}}=\frac{1}{k}\left[\ln \left(\frac{h-d}{z_{0}}\right)+\ln \left(c_{\mathrm{w}}\right)\right] .
$$

Subtracting eq 38 from 39 yields

$$
C_{\mathrm{Dz}_{\mathrm{w}}}^{-1 / 2}=C_{\mathrm{Dh}}^{-1 / 2}+\frac{1}{k}\left[\ln \left(c_{\mathrm{w}}\right)-\psi_{\mathrm{h}}\right] .
$$

On equating eq 37 and 40 , we finally can relate $C_{\mathrm{DN} 10}$ to $C_{\mathrm{Dh}}$

$$
C_{\mathrm{DN} 10}^{-1 / 2}=C_{\mathrm{Dh}}^{-1 / 2}+\frac{1}{k}\left[\ln \left(\frac{10-d}{h-d}\right)-\psi_{\mathrm{h}}\right] .
$$

We still do not know the displacement height $d$, however.

Thom (1971) identified $d$ as the effective level at which the roughness elements absorb the momentum being transferred to the surface. R92 used this definition to derive $d$. That is, if $d_{\mathrm{R}}$ is the centroid of the form drag on the roughness elements and if $d_{\mathrm{S}}$ is the centroid at which the skin friction acts

$$
d \tau=d_{\mathrm{R}} \tau_{\mathrm{R}}+d_{\mathrm{S}} \tau_{\mathrm{S}}=d_{\mathrm{R}} \tau_{\mathrm{R}}
$$

because $d_{\mathrm{S}}=0$ by definition. Thus

$$
d=d_{\mathrm{R}}\left(\tau_{\mathrm{R}} / \tau\right)
$$

Notice, from eq 19, 20 and 23

$$
\frac{\tau_{\mathrm{R}}}{\tau}=\frac{\lambda(\Phi) \hat{C}_{\mathrm{R}}(\Phi)}{C_{\mathrm{Sh}}+\lambda(\Phi) \hat{C}_{\mathrm{R}}(\Phi)} .
$$

$\mathrm{R} 92$ then related $d_{\mathrm{R}}$ to $h$. Following his arguments but applying them to the specific geometry of my model, I get

$$
d_{\mathrm{R}}=h-c_{\mathrm{d}} C_{\mathrm{Dh}}^{-1 / 2}[A(\Phi) / \lambda(\Phi)]^{1 / 2}
$$

in which $c_{\mathrm{d}}$ is a constant that R92 took to be 0.6. Inserting eq 5 in this and combining it with eq 43 yields

$$
d=h\left(\tau_{\mathrm{R}} / \tau\right)\left[1-c_{\mathrm{d}} C_{\mathrm{Dh}}^{-1 / 2}(m n / 2 \gamma)^{1 / 2}\right] .
$$

Thus, it is easy to find $\tau_{R} / \tau$ from eq 44 ; and once my model yields $C_{\mathrm{Dh}}$, it is simple to compute $d$. Using this value in eq 41 finally gives the quantity we seek, $C_{\mathrm{DN} 10}$.

I pointed out in the previous section that we need to convert $C_{\mathrm{S} 10}$ to $C_{\mathrm{Sh}}$ before we can begin computations. Equation 41 also makes this conversion. Unfortunately, we need $C_{S h}$ before we have obtained $d$. I could handle this problem by iterating the entire set of equations on $d$. But, as I will show in the next section, $d / h \approx 0.3$, a result also consistent with eq 46. At this step in the computations, this simple approximation is reasonable-especially in light of uncertainties in the other model parameters-because $C_{\mathrm{DN} 10}$ is not very sensitive to $C_{S 10}$ for the range of values that this parameter can realistically assume.

\section{RESULTS}

I have not yet discussed the value of $\gamma$, the fractional coverage of sastrugi-like roughness elements. Vladimir Churun* tried to quantify the roughness of the ISW floe using the radar on the Akademik Fedorov at the time the station was deployed. His survey suggested that hummock coverage varied over the floe from 10 to $30 \%$. While hummock coverage is not the same as sastrugi coverage, my personal experience on ISW suggests that $10-30 \%$ sastrugi coverage is also about right. Notice, because of the geometry of the sastrugi that I am modeling (Fig. 3), the tightest possible packing of roughness elements will yield a $\gamma$ value of only 0.5 . Thus, my first guess,

\footnotetext{
* Personal communication (Arctic and Antarctic Research Institute, St. Petersburg, Russia).
} 
$\gamma=0.15$, represents a conservative but not insignificantly small sastrugi coverage.

Figure 4 shows two sets of predictions for $C_{\text {DN10 }}$ as a function of $\Phi$ based on the model developed in the preceding section. Figure $4 \mathrm{a}$ shows computations of $C_{\mathrm{DN} 10}$ for $\gamma=0.15$ and for sastrugi heights of 5,10 and $20 \mathrm{~cm}$, typical heights represented in our snow-surface roughness surveys (e.g., Fig. 2). The $10-\mathrm{cm}$ case fits our observations quite well. Here, $C_{\mathrm{DN} 10}$ is $1.43-1.45 \times 10^{-3}$ when the flow is head-on or within $\pm 12^{\circ}$ of headon (that is, when $\Phi \lesssim \beta$ ). These values agree well with the nominal minimum value for $C_{\mathrm{DN} 10}$ of $1.5 \times 10^{-3}$ that we reported in AC95.

When $\Phi$ gets larger than $11.3^{\circ}$ (see eq 3 ), the wind can see the side ridge of the obstacle. In effect, it sees a larger silhouette area and a higher value of $C_{R} ; C_{D N 10}$ must thus increase. Figure 4 shows that if the wind rotates just $20^{\circ}$ from headon, $C_{\mathrm{DN} 10}$ will increase by $15-24 \%$, in good agreement with our observations in AC95.

As $\Phi$ increases and the wind thus has an in- creasing component perpendicular to the axis of the sastrugi, $C_{\mathrm{DN} 10}$ continues increasing. $C_{\mathrm{DN} 10}$ has its maximum at $\Phi=101.3^{\circ}$, where it is $2.73 \times 10^{-3}$ for the $\gamma=0.15$ and $h=10 \mathrm{~cm}$ case. Again, $m$ and $n$ set the location for this maximum; this is where $A(\Phi)$ has its maximum. The $C_{\mathrm{DN} 10}$ value there is in fair agreement with the maximum value that we observed on ISW, $2.54 \times 10^{-3}$ (AC95).

As $\Phi$ increases toward $180^{\circ}$, the model is entirely speculative, since we have few data with which to compare such a reversal in the wind and because $C_{\mathrm{R} 3}$ is the least certain of the form drag coefficients. For now, the decrease as $\Phi$ approaches $180^{\circ}$ seems reasonable because the silhouette area is decreasing rapidly. But the absolute values for $C_{\mathrm{DN} 10}$ in this region are certainly open to debate.

In Figure $4 a$, the calculations with $h$ values of 5 and $20 \mathrm{~cm}$ are less realistic than for $h=10 \mathrm{~cm}$. For $h=5 \mathrm{~cm}$, the maximum $C_{\mathrm{DN} 10}$ value calculated is $8 \%$ less than our observed maximum; for $h=20$ $\mathrm{cm}$, the calculated maximum is $27 \%$ higher than what we observed. For all three heights, however,

a. $\gamma=0.15$ (the sastrugi cover $15 \%$ of the surface) and $\mathrm{h}=5,10$, and $20 \mathrm{~cm}$.

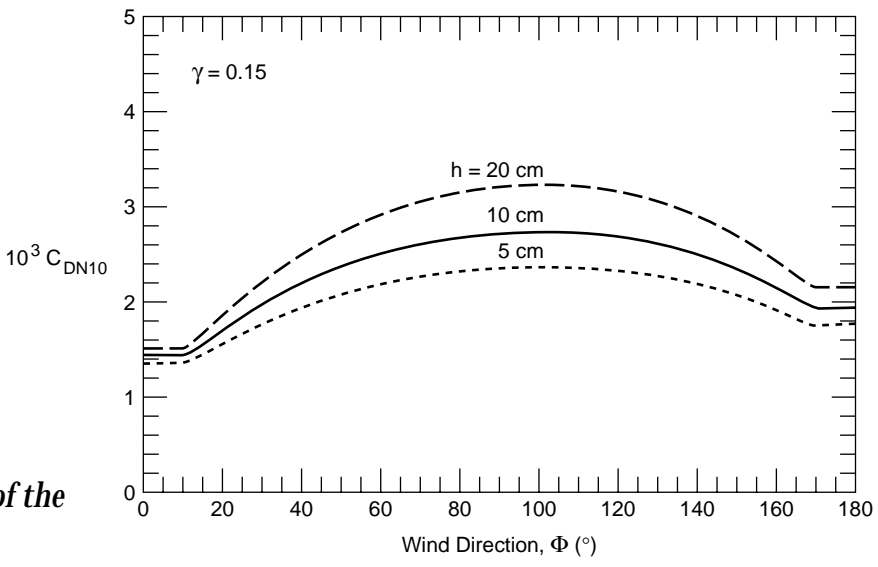

b. $\mathrm{h}=10 \mathrm{~cm}$ and $\gamma=0.10,0.15,0.20$, or 0.25 . Notice, the $\gamma=0.15$ line is the same as in Figure $4 a$

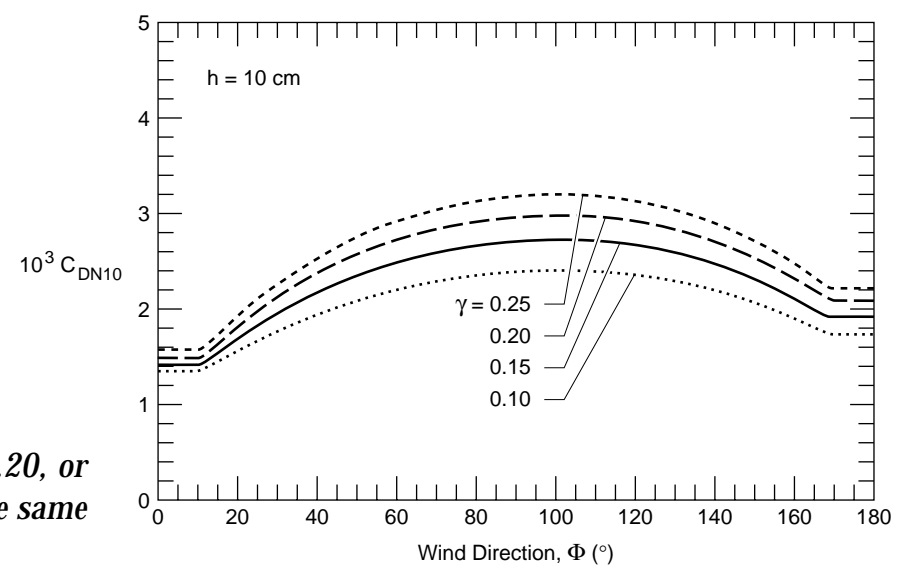

Figure 4. Model calculation of $\mathrm{C}_{D N 10}$ as a function of the wind orientation $(\Phi)$ with respect to the dominant axis of the sastrugi. Model parameters are $\mathrm{m}=4, \mathrm{n}=10, \mathrm{C}_{S 10}=1.10 \times 10^{-3}, \mathrm{C}_{R 1}=0.10$, $\mathrm{C}_{R 2}=0.30, \mathrm{C}_{\mathrm{R} 3}=0.30, \mathrm{c}=0.25, \mathrm{c}_{w}=4$ and $\mathrm{c}_{d}=0.6$. 
$C_{\text {DN10 }}$ values for head-on flow are in a reasonable range, $1.36-1.51 \times 10^{-3}$.

Figure $4 \mathrm{~b}$ investigates the sensitivity of the model to $\gamma$ when $h=10 \mathrm{~cm}$. For this value of $h$, $\gamma=0.10$ yields $C_{\mathrm{DN} 10}$ values for head-on flow of $1.36 \times 10^{-3}$. Although we did measure four $C_{\mathrm{DN} 10}$ values in this range, the more likely lower limit is about $1.5 \times 10^{-3}$. Also, as $\Phi$ increases, the predicted $C_{\mathrm{DN} 10}$ values reach a maximum that is $6 \%$ below our observed maximum. When $\gamma$ is 0.20 and 0.25 , the predicted head-on values for $C_{\mathrm{DN} 10}$ are roughly correct, $1.50-1.55 \times 10^{-3}$. But for these $\gamma$ values, the maximum predicted values are, respectively, 17 and $26 \%$ above our observed maximum. Notice, $\gamma=0.25$ means that the sastrugi cover half the area that they would if they were packed as tightly as possible. This value is, therefore, probably an unrealistically large sastrugi coverage for ISW.

For the $\gamma=0.15$ and $h=10 \mathrm{~cm}$ case-the one that fits the data best-I also ran the model with $C_{S 10}=1.00 \times 10^{-3}$ (not shown), roughly the smallest value compatible with the surveys I cited earlier. Resulting predictions for $C_{\mathrm{DN} 10}$ were $4-6 \%$ lower for $0^{\circ} \leq \Phi \leq 20^{\circ}$ and for $160^{\circ} \leq \Phi \leq 180^{\circ}$ than for calculations based on $C_{\mathrm{S} 10}=1.10 \times 10^{-3}$. For

Figure 5. Stress partitioning, $\tau_{\mathrm{R}} / \tau$, versus the mean wind direction with respect to the dominant axis of the sastrugi. Realize that $\tau_{S} / \tau=1-\tau_{R} / \tau$. Here, $\gamma$ is the fractional sastrugi coverage, and $\mathrm{h}$ is the sastrugi height in centimeters.

Figure 6. Computed displacement height d scaled by sastrugi height $\mathrm{h}$ versus the direction of the mean wind with respect to the sastrugi. Here, $\gamma$ is the fractional sastrugi coverage, and $\mathrm{h}$ is in centimeters. $30^{\circ} \leq \Phi \leq 160^{\circ}$, the differences were only $2-3 \%$. Consequently, the choice of $C_{S 10}$ does not have a big effect on the results, as long as the value is a reasonable one. Secondly, my handling of the displacement height in converting from $C_{\mathrm{S} 10}$ to $C_{\mathrm{Sh}}$ is appropriate, given this weak sensitivity to $C_{\mathrm{S} 10}$.

Figure 5 shows some examples of how the stress is partitioned between form drag and skin friction. I plot $\tau_{R} / \tau$; clearly, $\tau_{S} / \tau=1-\tau_{R} / \tau$. In the figure, the $(\gamma=0.10, h=10 \mathrm{~cm})$ and the $(\gamma=0.20$, $h=20 \mathrm{~cm}$ ) lines, respectively, show the minimum and maximum values of $\tau_{R} / \tau$ that I obtained for the range of model parameters considered. My computations suggest that, even for a very rough surface, $\gamma=0.20$ and $h=20 \mathrm{~cm}$, skin friction produces more than half of the total stress when the flow is approximately head-on. In other words, the streamlined shape of the sastrugi is quite effective at reducing form drag. When the flow is at right angles to the sastrugi, however, form drag dominates the total stress because the wind has so much more surface to push against. This dominance of form drag for such wind orientations explains why the drifts erode so quickly (AC95).

Equation 46 yields the displacement height; Figure 6 shows several computations of $d / h$. For
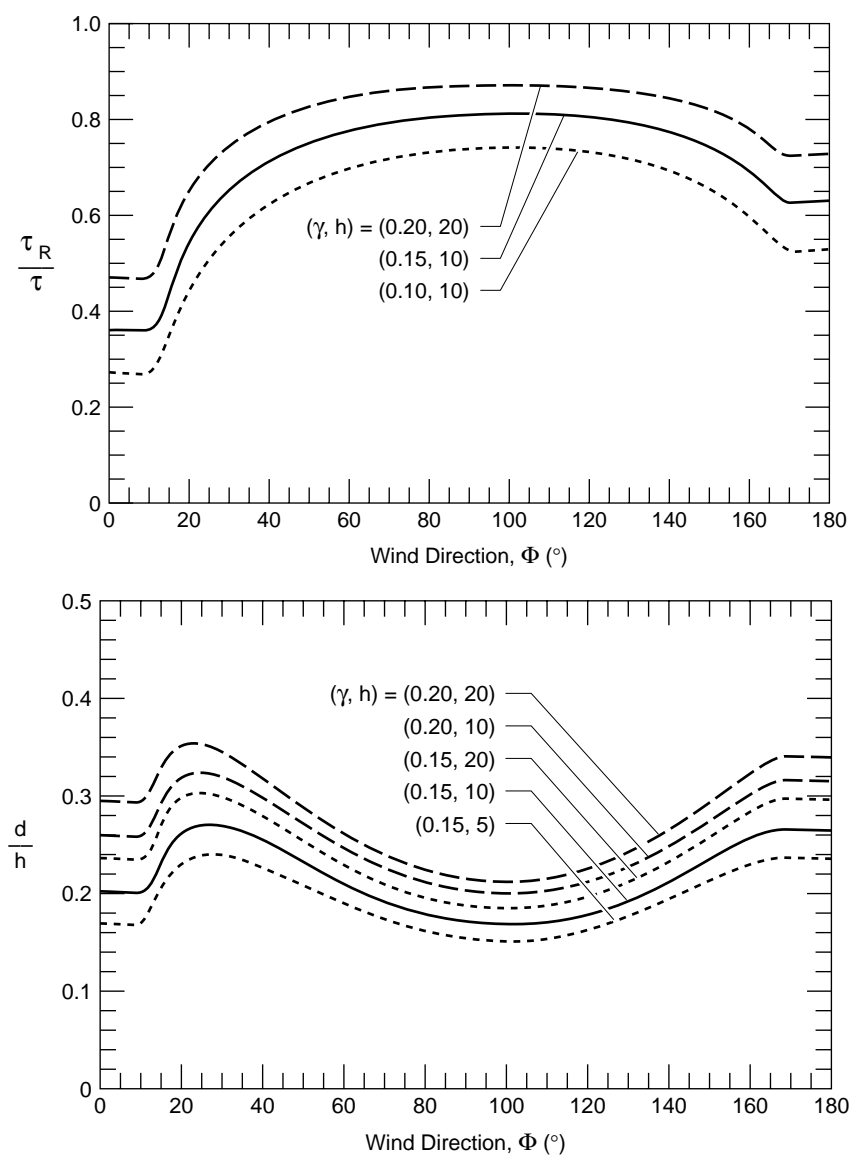
densely packed roughness elements, such as crops, trees or other vegetation, $d / h$ is typically reported to be about 0.7 (Stanhill 1969, Thom 1971, Fazu and Schwerdtfeger 1989). For the more widely spaced sastrugi that I am considering, however, $d / h$ is $0.15-0.35$. This is also roughly what R92 (his Figure 5) computed for $\lambda$ values in the range relevant to this problem, $0.01-0.06$.

These plots justify my use of $d / h=0.3$ when I had to convert $C_{\mathrm{S} 10}$ to $C_{\mathrm{Sh}}$ in the section on Partitioning the Stress. They also show that, for sastrugi typically $10 \mathrm{~cm}$ high, $d$ is usually less than 3 $\mathrm{cm}$. We were thus safe to ignore $d$ in analyzing our wind speed profiles in AC95. For the lowest profiling level used in AC95, $0.5 \mathrm{~m}$, including a displacement height of $3 \mathrm{~cm}$ in a computation based on eq 29 would yield a $u_{*}$ value roughly $1 \%$ larger than a computation with $d=0$. For the higher levels, the difference would be even less. Since the nominal uncertainty in our wind speed measurements was $\pm 5 \mathrm{~cm} / \mathrm{s}$, this small bias in our computations is negligible.

Figure 6 shows that $d$ has some interesting structure-it is not a constant for all wind directions. Equation 46 explains this behavior: $d / h$ responds mainly to two variables, $\tau_{\mathrm{R}} / \tau$ and $C_{\mathrm{Dh}}$; $d / h$ increases linearly with $\tau_{R} / \tau$ but decreases linearly with $C_{\mathrm{Dh}}^{1 / 2}$. The peak in $d / h$ near 20-30 corresponds to the rapid increase in $\tau_{R} / \tau$ in this range (Fig. 5), while the broad minimum centered near $100^{\circ}$ is where $C_{\mathrm{Dh}}$ has its maximum (Fig. 4). Another curious feature in Figure 6 is that the $d$ values in this broad minimum are usually less than the values for head-on flow. Clearly, $d$ does not change in concert with $z_{0}$ or $C_{\mathrm{Dh}}$ - parameters that quantify the aerodynamic roughness of the surface. This is an important conclusion because others have claimed that $d$ is a linear function of $z_{0}$ (e.g., Brutsaert 1982, p. 113; Sugita and Brutsaert 1990).

In summary, the Raupach's Model Adapted to Drifting Snow section explains that my adaptation of R92's model has 11 adjustable parameters: $h, m, n, \gamma, C_{\mathrm{S} 10}, C_{\mathrm{R} 1}, C_{\mathrm{R} 2}, C_{\mathrm{R} 3}, c, c_{\mathrm{W}}$ and $c_{\mathrm{d}}$. With reasonable choices for these and with little finetuning, I have demonstrated that that model fits our ISW observations quite well. I do not mean to imply here, however, that the model is infallibly accurate-only that it seems to capture the essential physics of how wind transfers momentum to snow-covered sea ice.

\section{DISCUSSION}

\section{Primary roughness elements}

The obvious (and, perhaps, surprising) conclusion from the calculations described in the last section is that roughness elements with heights of only $10 \mathrm{~cm}$ can have a dominant effect on $C_{\mathrm{DN} 10}$. This is essentially the same conclusion that Jackson and Carroll (1978) reached. Arya's (1973, 1975) model, in contrast, predicted that pressure ridges 1 to $4 \mathrm{~m}$ high accounted for most of the form drag that determined the large-scale roughness and drag coefficient over Arctic sea ice.

My calculations provide a theoretical basis for the empirical result that Banke et al. $(1976,1980)$ obtained, eq 1. Their roughness parameter $\xi$ reflects the small-scale roughness; they reported $\xi$ values of $3-13 \mathrm{~cm}$, where $\xi$ came from integrating the roughness spectrum over all wavelengths shorter than $13 \mathrm{~m}$ (also see Andreas et al. 1993). Such wavelengths are far smaller than either Arctic or Antarctic ridge spacings (Lytle and Ackley 1991). Thus, eq 1 and my calculations point to the same conclusion: Pressure ridges are relatively unimportant in setting the local drag coefficient; $C_{\mathrm{DN} 10}$ responds primarily to sastrugi-size roughness elements. Pressure ridges, however, will probably be important in establishing an areally averaged or effective roughness length, $Z_{0}$. Fiedler and Panofsky (1972), Arya (1975), Overland (1985), and Claussen (1991), among others, have offered some thoughts on inferring $Z_{0}$ from $z_{0}$. But pursuing that connection is beyond my scope here.

\section{Parameterizing the drag coefficient}

These model results and the behavior of $C_{\mathrm{DN} 10}$ over snow-covered sea ice that we documented in AC95 suggest what might be necessary in a scheme for parameterizing $C_{\mathrm{DN} 10}$. The snow surface is not in general isotropic, especially during, or for some time after, high wind events. The wind builds sastrugi and therefore streamlines the surface in the mean wind direction. Figure 4 shows how $C_{\mathrm{DN} 10}$ behaves for various wind directions once the surface has been streamlined.

Thus, the key is to estimate the dominant direction of the sastrugi without the benefit of in situ observations. Maybe in the future, satellites will provide real-time information on ice-surface roughness, including any preferential alignment of the roughness elements. But for now, all we can 
do is estimate the orientation of roughness elements by tracking the history of surface winds that have been inferred from analyzed geostrophic winds. According to AC95, if the surface wind blows at $8 \mathrm{~m} / \mathrm{s}$ or higher with constant direction, it will build sastrugi parallel to it and, thus, streamline the surface. If such conditions persist for 12 hours, $C_{\mathrm{DN} 10}$ will fall from its initial value to about $1.5 \times 10^{-3}$ and will remain here as long as the wind remains aligned with the sastrugi.

If subsequent surface winds fall below $6 \mathrm{~m} / \mathrm{s}$, Figure 4 shows how $C_{\mathrm{DN} 10}$ will vary as the wind turns with respect to the axis of the sastrugi.

The difficult part of the parameterization will be treating directionally variable winds of $6-8 \mathrm{~m} / \mathrm{s}$, or higher. These are strong enough to begin reworking the surface-eroding the snowdrifts present-but, because of their variability, will not necessarily build new drifts and thereby streamline the surface in another direction. Neither the data in AC95 nor the model developed here provides a clear suggestion on how to evaluate $C_{\mathrm{DN} 10}$ for such winds.

In summary, except for the complication just mentioned, it seems possible to now estimate $C_{\mathrm{DN} 10}$ over snow-covered sea ice by tracking the history of the surface wind computed from analyzed pressure fields. I have described the algorithm in words; coding and testing it is the next step.

\section{CONCLUSIONS}

I have adapted R92's model for the form drag on a field of interacting roughness elements and applied it to rudimentary sastrugi-like snowdrifts. The key step was treating the complex geometry of the sastrugi. In the absence of laboratory values for the form drag on the various faces of the sastrugi, I assumed that the form drag reflects additive contributions from the various faces of the individual sastrugi (see eq 13).

The resulting model does quite well in reproducing the values of $C_{\mathrm{DN} 10}$ that we observed in AC95. For sastrugi of height $10 \mathrm{~cm}$ and with an areal coverage of $15 \%$, the model predicts that $C_{\mathrm{DN} 10}=1.43 \times 10^{-3}$ when $\Phi$ is less than $12^{\circ}$. In AC95, the nominal head-on value of $C_{\mathrm{DN} 10}$ that we observed was $1.5 \times 10^{-3}$. In the model, as $\Phi$ gets larger than $12^{\circ}, C_{\mathrm{DN} 10}$ increases rapidly. In this example, $C_{\mathrm{DN} 10}$ increases by $17 \%$ as $\Phi$ turns from 12 to $20^{\circ}$. As $\Phi$ continues increasing, $C_{\mathrm{DN} 10}$ eventually reaches a maximum of $2.73 \times 10^{-3}$ at
$\Phi=101.3^{\circ}$. This increase with $\Phi$ also mirrors the directional sensitivity we reported in AC95, though the predicted maximum is about $7 \%$ higher than our measured maximum for $C_{\mathrm{DN} 10}$, $2.54 \times 10^{-3}$.

The upshot of this modeling is that the small, 10-cm-high roughness elements associated with drifting snow-rather than pressure ridges or other mesoscale features-determine the local drag coefficient over snow-covered sea ice. Though some have stated this conclusion explicitly (e.g., Joffre 1982) or implicitly (e.g., Banke et al. 1976, 1980), my model is the first to provide a theoretical foundation for it.

These model predictions and the observations in AC95 suggest how we should attempt to parameterize $C_{\mathrm{DN} 10}$ in terms of what we can measure. Because $C_{\mathrm{DN} 10}$ depends crucially on how the mean wind is oriented with respect to the sastrugi, the key is predicting sastrugi orientation. Our observations showed that this orientation depends on the history of the surface wind. By inferring surface winds from analyzed fields of the geostrophic wind, we should be able to deduce this orientation. The event to look for is a directionally constant surface wind of at least $8 \mathrm{~m} / \mathrm{s}$ that persists for 12 hours. At the end of such an event, $C_{\mathrm{DN} 10}$ will be roughly $1.5 \times 10^{-3}$. Figure 4 then shows how to estimate $C_{\mathrm{DN} 10}$ when the wind direction subsequently changes.

\section{LITERATURE CITED}

Allen, J.R.L. (1965) Scour marks in snow. Journal of Sedimentary Petrology, 35: 331-338.

Andreas, E.L and K.J. Claffey (1995) Air-ice drag coefficients in the western Weddell Sea: 1 . Values deduced from profile measurements. Journal of Geophysical Research, 100: 4821-4831.

Andreas, E.L, M.A. Lange, S.F. Ackley and P. Wadhams (1993) Roughness of Weddell Sea ice and estimates of the air-ice drag coefficient. Journal of Geophysical Research, 98: 12,439-12,452.

Arie, M. and H. Rouse (1956) Experiments on twodimensional flow over a normal wall. Journal of Fluid Mechanics, 1: 129-141.

Arya, S.P.S. (1973) Contribution of form drag on pressure ridges to the air stress on Arctic ice. Journal of Geophysical Research, 78: 7092-7099.

Arya, S.P.S. (1975) A drag partition theory for determining the large-scale roughness parameter and wind stress on the Arctic pack ice. Journal of Geophysical Research, 80: 3447-3454. 
Banke, E.G. and S.D. Smith (1973) Wind stress on Arctic sea ice. Journal of Geophysical Research, 78: 7871-7883.

Banke, E.G., S.D. Smith and R.J. Anderson (1976)

Recent measurements of wind stress on Arctic sea ice. Journal of the Fisheries Research Board of Canada, 33: 2307-2317.

Banke, E.G., S.D. Smith and R.J. Anderson (1980) Drag coefficients at AIDJEX from sonic anemometer measurements. In Sea Ice Processes and Models (R.S. Pritchard, Ed.). Seattle: University of Washington Press, p. 430-442.

Brutsaert, W.H. (1982) Evaporation into the Atmosphere: Theory, History and Applications. Dordrecht: D. Reidel.

Claussen, M. (1991) Estimation of areally-averaged surface fluxes. Boundary-Layer Meteorology, 54: 387-410.

Fazu, C. and P. Schwerdtfeger (1989) Flux-gradient relationships for momentum and heat over a rough natural surface. Quarterly Journal of the Royal Meteorological Society, 115: 335-352.

Fiedler, F. and H.A. Panofsky (1972) The geostrophic drag coefficient and the 'effective' roughness length. Quarterly Journal of the Royal Meteorological Society, 98: 213-220.

Finney, E.A. (1939) Snow drift control by highway design. Engineering Experiment Station, Michigan State College, East Lansing, Bulletin 86.

Jackson, B.S. and J.J. Carroll (1978) Aerodynamic roughness as a function of wind direction over asymmetric surface elements. Boundary-Layer Meteorology, 14: 323-330.

Joffre, S.M. (1982) Momentum and heat transfers in the surface layer over a frozen sea. BoundaryLayer Meteorology, 24: 211-229.

Kondo, J. and H. Yamazawa (1986) Bulk transfer coefficient over a snow surface. Boundary-Layer Meteorology, 34: 123-135.

Kutzbach, J.E. (1961) Investigation of the modification of wind profiles by artificially controlled surface roughness. In Annual Report 1961, Department of Meteorology, University of Wisconsin, Madison, p. 71-113.
Lettau, H. (1969) Note on aerodynamic roughness-parameter estimation on the basis of roughness-element description. Journal of Applied Meteorology, 8: 828-832.

Lytle, V.I. and S.F. Ackley (1991) Sea ice ridging in the eastern Weddell Sea. Journal of Geophysical Research, 96: 18,411-18,416.

Mellor, M. (1965) Blowing snow. USA Cold Regions Research and Engineering Laboratory, Cold Regions Science and Engineering Monograph, Part III, Section A3c.

Overland, J.E. (1985) Atmospheric boundary layer structure and drag coefficients over sea ice. Journal of Geophysical Research, 90: 9029-9049.

Owen, P.R. (1964) Saltation of uniform grains in air. Journal of Fluid Mechanics, 20: 225-242.

Plate, E.J. (1971) Aerodynamic Characteristics of Atmospheric Boundary Layers. Oak Ridge, Tennessee: U.S. Atomic Energy Commission.

Radok, U. (1968) Deposition and erosion of snow by the wind. USA Cold Regions Research and Engineering Laboratory, Research Report 230.

Raupach, M.R. (1992) Drag and drag partition on rough surfaces. Boundary-Layer Meteorology, 60: 375-395.

Raupach, M.R., D.A. Gillette and J.F. Leys (1993) The effect of roughness elements on wind erosion threshold. Journal of Geophysical Research, 98: 3023-3029.

Stanhill, G. (1969) A simple instrument for the field measurement of turbulent diffusion flux. Journal of Applied Meteorology, 8: 509-513.

Sugita, M. and W. Brutsaert (1990) Wind velocity measurements in the neutral boundary layer above hilly prairie. Journal of Geophysical Research, 95: 7617-7624.

Taylor, P.A. (1988) Turbulent wakes in the atmospheric boundary layer. In Flow and Transport in the Natural Environment: Advances and Applications (W.L. Steffen and O.T. Denmead, Eds.). Berlin: Springer-Verlag, p. 270-292.

Thom, A.S. (1971) Momentum absorption by vegetation. Quarterly Journal of the Royal Meteorological Society, 97: 414-428. 


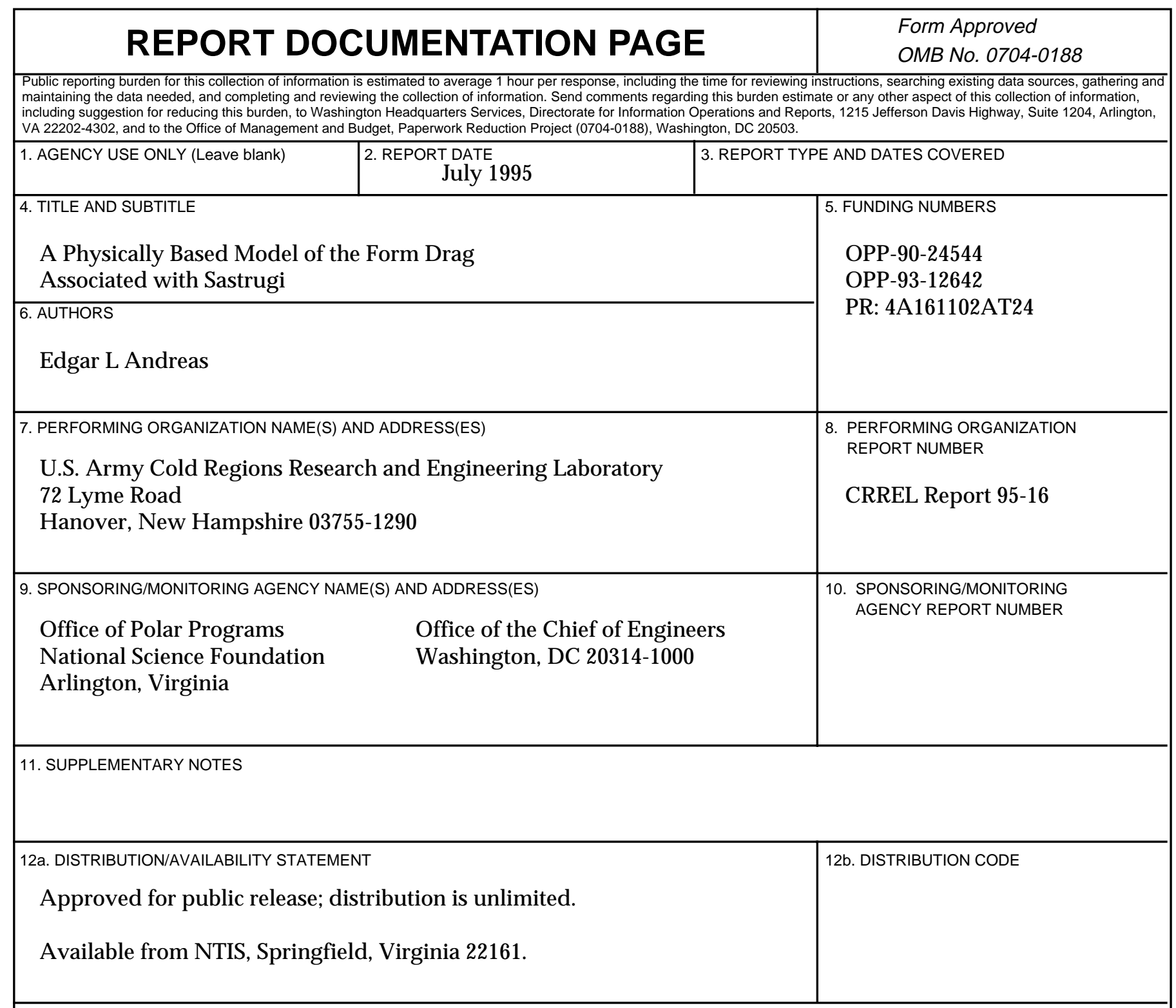

13. ABSTRACT (Maximum 200 words)

On Ice Station Weddell, some characteristics of the neutral-stability air-ice drag coefficient at a reference height of $10 \mathrm{~m}\left(C_{\mathrm{DN} 10}\right)$ were observed that had not been documented before. The main finding was that winddriven snow continually alters the sea ice surface; the resulting snowdrifts determine how large $C_{\mathrm{DN} 10}$ is. In particular, this report describes three observations and attempts to explain them: 1) $C_{\mathrm{DN} 10}$ is near $1.5 \times 10^{-3}$ when the wind is well aligned with the drifted snow; 2) $C_{\mathrm{DN} 10}$ is near $2.5 \times 10^{-3}$ when the wind makes a large angle with the dominant orientation of the snowdrifts; 3) $C_{\mathrm{DN} 10}$ can increase by $20 \%$ if, after being well aligned with the drift patterns, the mean wind direction shifts by as little as $20^{\circ}$. To investigate this behavior of $C_{\mathrm{DN} 10}$, this report adapts a model developed by Raupach that partitions the total surface stress into contributions from form drag and skin friction. With reasonable choices for free model parameters and with little fine-tuning, this physically based model can reproduce the three main observations. In other words, the model seems to include the basic physics of air-ice momentum exchange. This modeling implies that $10-\mathrm{cm}$-high sastrugilike roughness elements, rather than pressure ridges, sustain most of the form drag over compact sea ice in the western Weddell Sea. Lastly, the report speculates on what the observations and this model say about how to parameterize $C_{\mathrm{DN} 10}$ over snow-covered sea ice.

\begin{tabular}{|c|c|c|c|}
\hline \multirow{2}{*}{$\begin{array}{l}\text { 14. SUBJECT TERMS } \\
\text { Air-sea-ice interaction } \\
\text { Drag coefficient } \\
\text { Drifting snow }\end{array}$} & \multirow{2}{*}{\multicolumn{2}{|c|}{$\begin{array}{l}\text { Form drag } \\
\text { Snow drifts } \\
\text { Weddell Sea }\end{array}$}} & 15. NUMBER OF PAGES \\
\hline & & & 16. PRICE CODE \\
\hline $\begin{array}{l}\text { 17. SECURITY CLASSIFICATION } \\
\text { OF REPORT }\end{array}$ & $\begin{array}{l}\text { 18. SECURITY CLASSIFICATION } \\
\text { OF THIS PAGE }\end{array}$ & $\begin{array}{l}\text { 19. SECURITY CLASSIFICATION } \\
\text { OF ABSTRACT }\end{array}$ & 20. LIMITATION OF ABSTRACT \\
\hline UNCLASSIFIED & UNCLASSIFIED & UNCLASSIFIED & UL \\
\hline
\end{tabular}

